Supplementary information

\title{
Model Study on the Ideal Current-voltage Characteristics and Rectification Performance of Molecular Rectifier under Single Level based Tunneling and Hopping Transport
}

\author{
Xianneng Song, $\mathrm{Xi} Y u^{*}$ and Wenping $H u^{*}$
}

Tianjin Key Laboratory of Molecular Optoelectronic Science, School of Science, Tianjin University, Tianjin300072, China.

*Corresponding author E-mail: xi.yu@tju.edu.cn and huwp@tju.edu.cn 


\section{Potential distribution}

Here, we mainly discuss the potential distribution along the molecular junction. The molecular wire can be modeled as a cylinder of length $\mathrm{L}$ and diameter of order $\mathrm{D}$, perpendicular to and connecting between two planar metal electrode surfaces ${ }^{1}$. This model is as shown in Figure S1. In this case, the potential profile along the wire can be describe as

$$
\Phi(x)=\Phi_{0}(x)-\frac{\Delta}{\pi} \sum_{n=1}^{\infty} \frac{F_{n}}{n\left(1+F_{n}\right)} \sin \left(\frac{2 \pi n}{L} x\right)
$$

Where, $\Delta$ is the setting potential. The first term is the bare potential and is described by

$$
\Phi_{0}(x)=\Delta\left(\frac{1}{2}-\frac{z}{L}\right)
$$

The coefficients $F_{n}$ accounting for the influence of screening are given by

$$
F_{n}=\frac{1}{2}\left(\frac{D}{\lambda}\right)^{2} e^{\chi} \int_{\chi}^{\infty} d u \frac{e^{-u}}{u}
$$

with

$$
\chi=\frac{1}{2}\left(2 \pi n \frac{D}{L}\right)^{2}
$$

The $\lambda$ is screening length that is used to describe the screening capacity of molecular wires ${ }^{2}$. And the limit $\lambda \rightarrow \infty \quad D \rightarrow 0$ lead to near-linear voltage drop, $\lambda \rightarrow 0 \quad D \rightarrow \infty$ lead to nonlinear behavior. The nonlinear voltage drop is shown in Figure S2. Based on this potential profile, we have given the I-V characteristics for different parameters as shown in Figure S4 and the position of active center and other parameters are set same as the linear case. 


\section{Value of coupling strength used in the text.}

In this section, we provide justification for the values of coupling strength used in the mixed model, that is, the coupling strength $\Gamma$ in eq 3 and rate $\mathrm{k}$ in eq 5-6.

We first demonstrate that $\Gamma$ in eq 3 and rate $\mathrm{k}$ in eq 5-6 are correlated and should be chosen reasonably. Generally, the coupling strength in tunneling process is defined as

$$
\Gamma_{K}=\pi\left|M_{o / r}^{K}\right|^{2} \rho_{K}(E)
$$

where the $M_{o / r}^{K}$ is transfer integral, $\rho_{K}(E)$ is the density of electrons in the electrodes.

On the other hand, the rate $\mathrm{k}$ in Marcus type process has followed form following Fermi golden formula:

$$
k_{K}(E)=\frac{2 \pi}{\hbar}\left|M_{o / r}^{K}\right|^{2} \rho_{K}(E)
$$

By comparing eq S1(eq 17) and S2(7), we can get the relationship between $\Gamma_{K}$ and $k_{K}$

$$
k_{K}=\frac{2 \Gamma_{K}}{\hbar}
$$

This relationship between $\mathrm{k}$ and $\Gamma$ was also demonstrated by previous work in the references 6,7 as well. According to above description, we can choose the values of two parameters under a unified framework. Then we turn to discuss the selection of the value of $\mathrm{k}$ and $\Gamma$ in the mixed model.

In the main text, we define the relationship between the length of spacer and coupling strength as

$$
\Gamma_{K}=\mathrm{C} e^{-\beta L_{K}}
$$

$\mathrm{C}$ is contact coupling constant (coupling at zero spacer length), and $\beta$ is the attenuation coefficient and is the measure of decay rate with respect to the length of the bridge molecule ${ }^{8}$. 
It also applies to the rate $\mathrm{k}$ in the hopping. Therefore, we need to select $\mathrm{C}$ by combining experiment results and dependence of coupling strength on spacer length.

In the previous charge transfer dynamic measurement done based on electrochemistry ${ }^{9-11}$, the rate of $\mathrm{k}$ consisting of Fc group with different length alkyl chain has been inferred. According to reference 10 and 11, the $k$ of a Fc group connected to Au via a spacer of 16 carbon units and a thiol anchoring group is reported to be $6.73 \times 10^{4} \mathrm{~s}^{-1}$. Hence, if we assume the attenuation coefficient $\beta$ in eq.S4(eq. 16) as 1.1 per carbon atom (This value varied a bit depending on the measurement and 1.1 is a well acceptable averaged value ${ }^{10,12,13}$ ), the $\mathrm{C}$ can be obtained by combining eq.S4 and eq.S3, that is $0.057 \mathrm{eV}$ (The corresponding value of $\mathrm{k}$ is $1.72 \times 10^{13} \mathrm{~s}^{-1}$ ).

However, this value seems much smaller than the coupling strength between Fc and metal electrodes when the Fc directly connects to the electrode by a thiol bond ${ }^{3,14}$. Therefore, we take the value of coupling strength reported by Nijhuis.et $\mathrm{al}^{3,14}$ as the value of C (roughly take the coupling strength between $\mathrm{Fc}$ and $\mathrm{Ag}$ as $0.35 \mathrm{eV}\left(C_{\text {Bottom }}\right)$, and $0.05 \mathrm{eV}\left(C_{T o p}\right)$ for between $\mathrm{Fc}$ and EGaIn), and then derive the rate $k$ in the hopping transport path (the $\mathrm{k}$ corresponding to $C_{\text {Bottom }}$ and $C_{\text {Top }}$ are $1.06 \times 10^{15} \mathrm{~s}^{-1}$ and $1.52 \times 10^{14} \mathrm{~s}^{-1}$, respectively).

We want to emphasize again that in our model, we assume coexisting tunneling and hopping channels, sharing the same chemical structures, should possess correlated coupling strength values for the two channels, instead of independent different values that has been used in previous work 6 . 


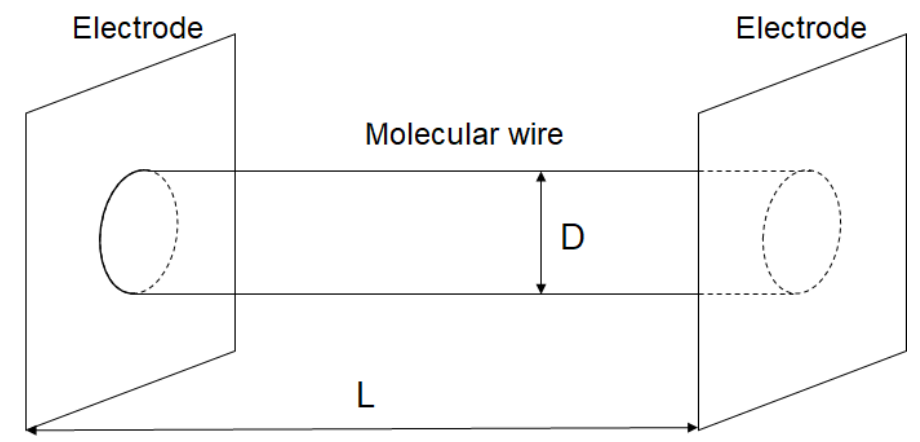

Figure S1. The general setup contains a molecular wire modeled as a cylinder

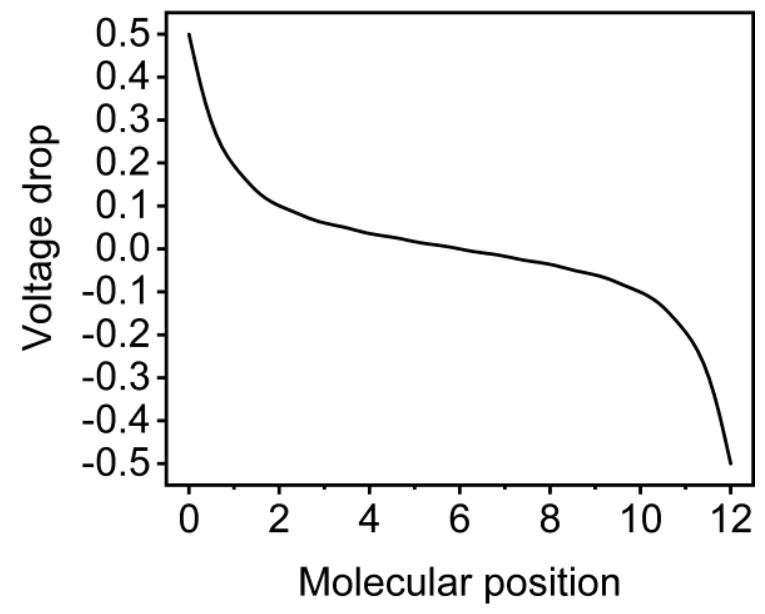

Figure S2. The voltage drop along a molecular wire is shown for alkyl chain that contains 12 carbons by applying $1 \mathrm{~V}$. The screening length is $1.5 \AA$ and the diameter of the wire is $2.38 \AA$. 


$$
\alpha=6 / 12
$$
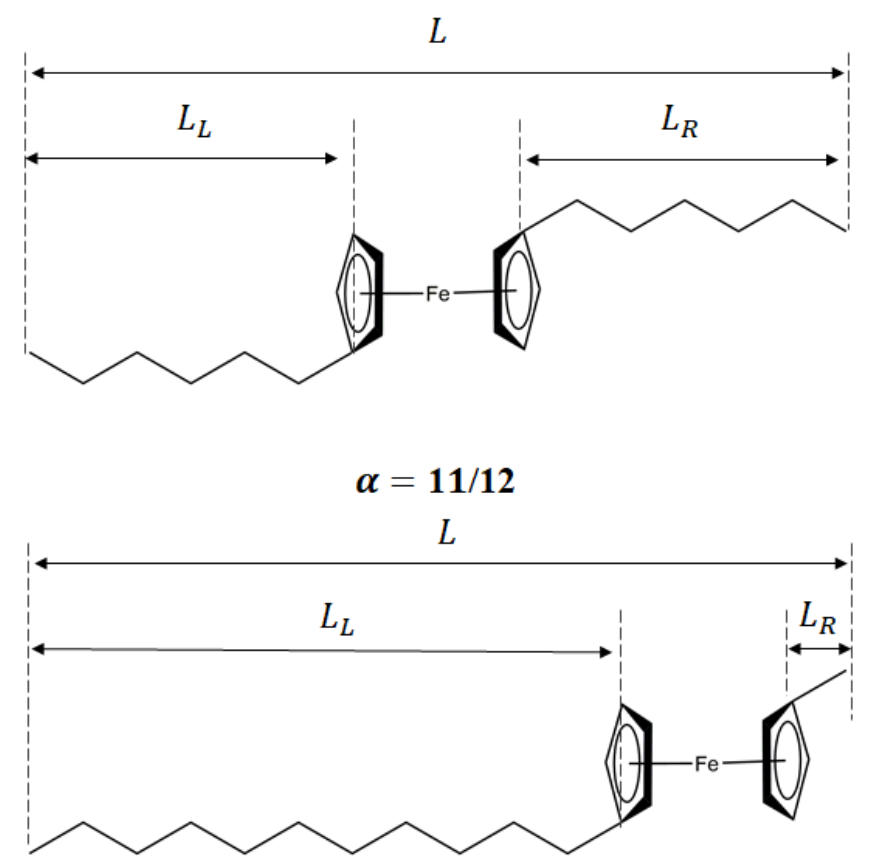

Figure S3 Molecular structure with active centers inserted into different positions and the voltage division factors are $\alpha=6 / 12$ and $\alpha=11 / 12$
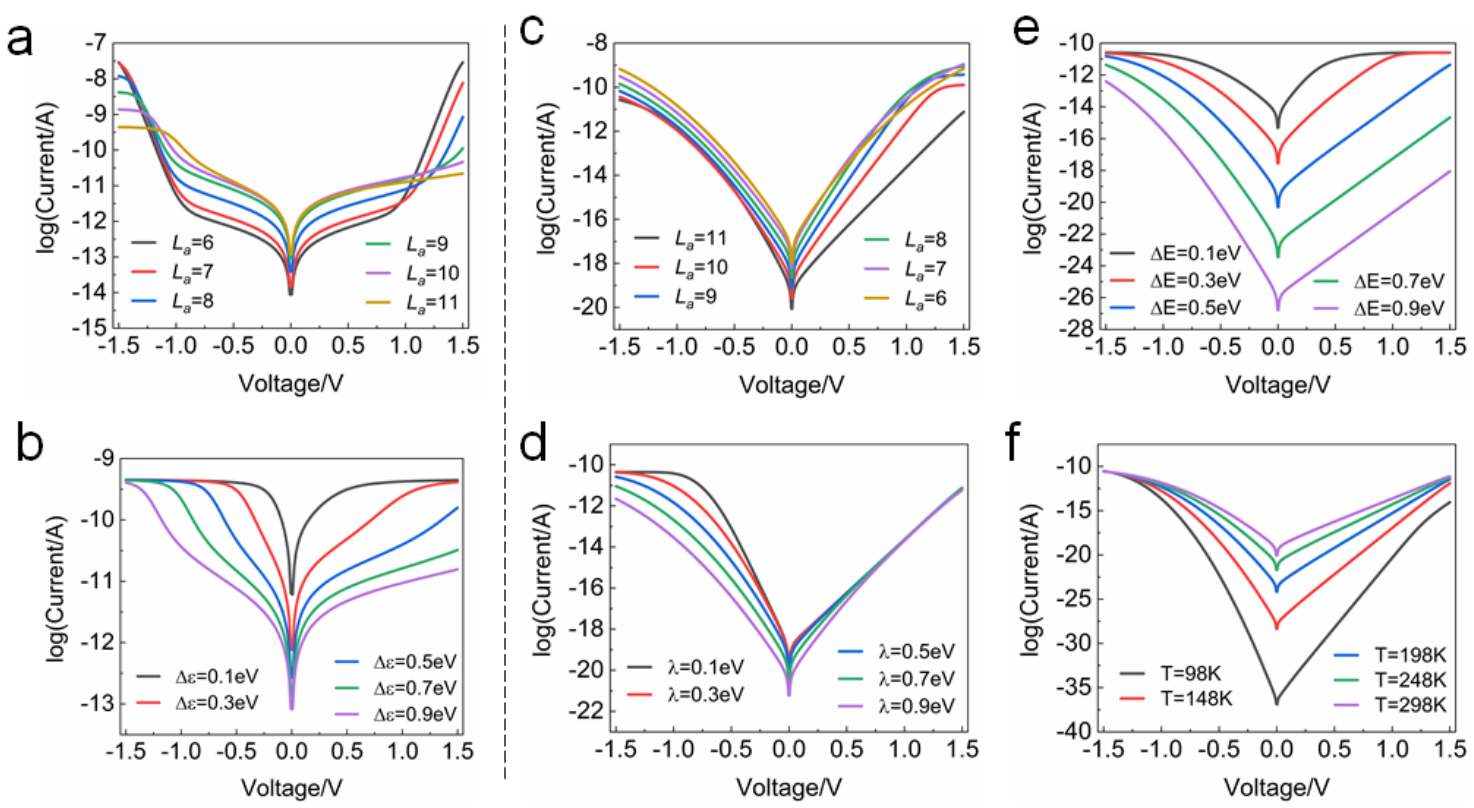

Figure S4. The I-V characteristic of tunneling transport for position of active center (a) and energy barrier(b) and hopping transport for different parameters in nonlinear potential distribution: position of active center (c), energy barrier (d), reorganization energy (e) temperature (f) in semi-log scale. 


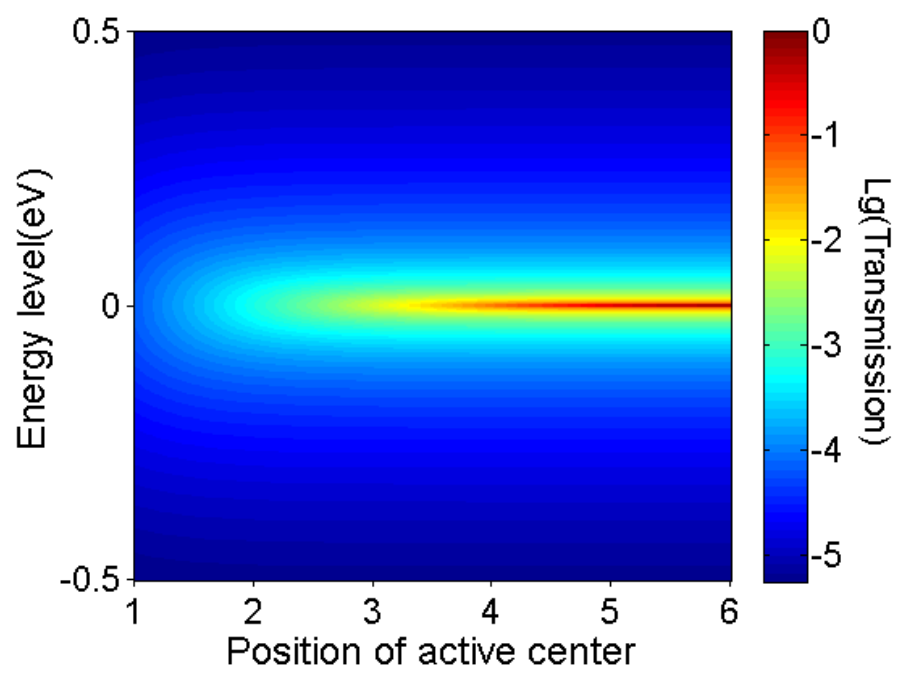

Figure S5 Transmission function change with voltage division factor and the molecular energy level sets to zero
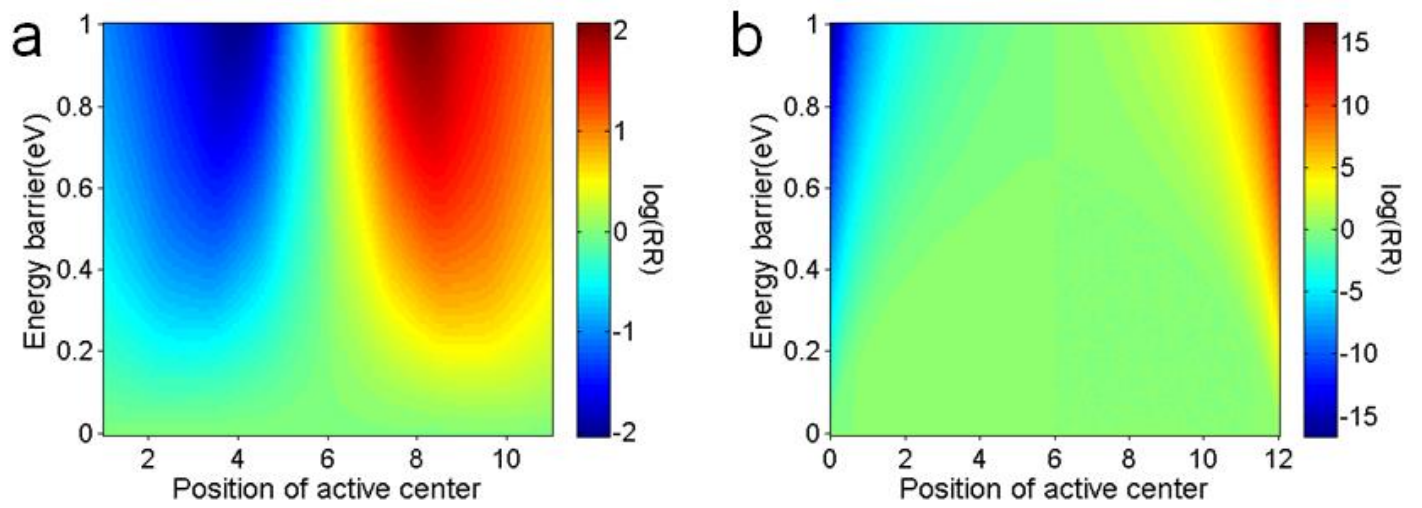

Figure S6. Variation of maximum rectification ratio with energy barrier and position of active center. This position represents the number of carbon atoms spaced between the active center and the right electrode. (a) Tunneling transport under nonlinear potential distribution, (b) Hopping transport under nonlinear potential distribution. 

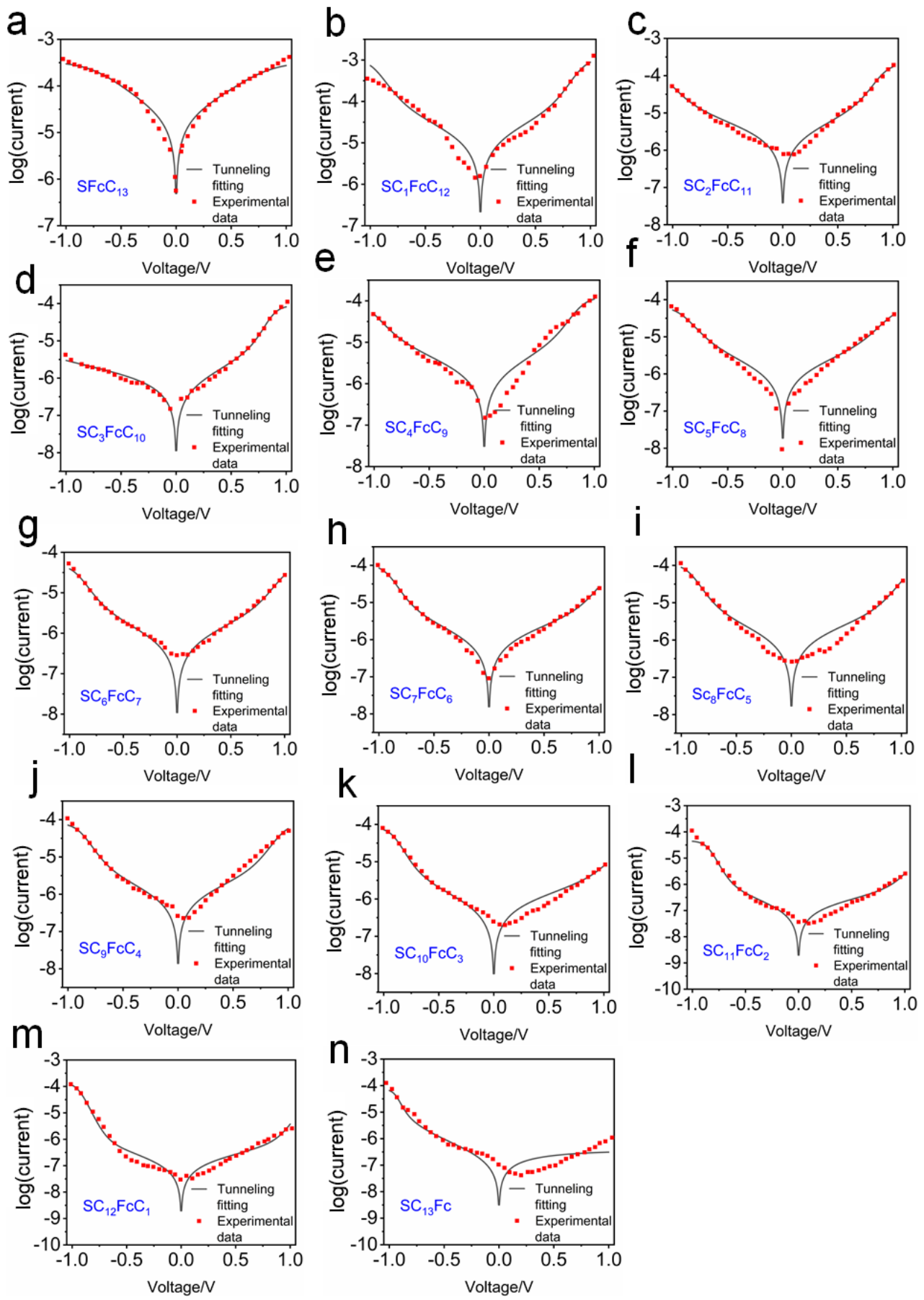

Figure S7. All fitting results by using tunneling model for ferrocenyl-alkanethiol selfassembled monolayer (data extract from ref 4 in the main text). 

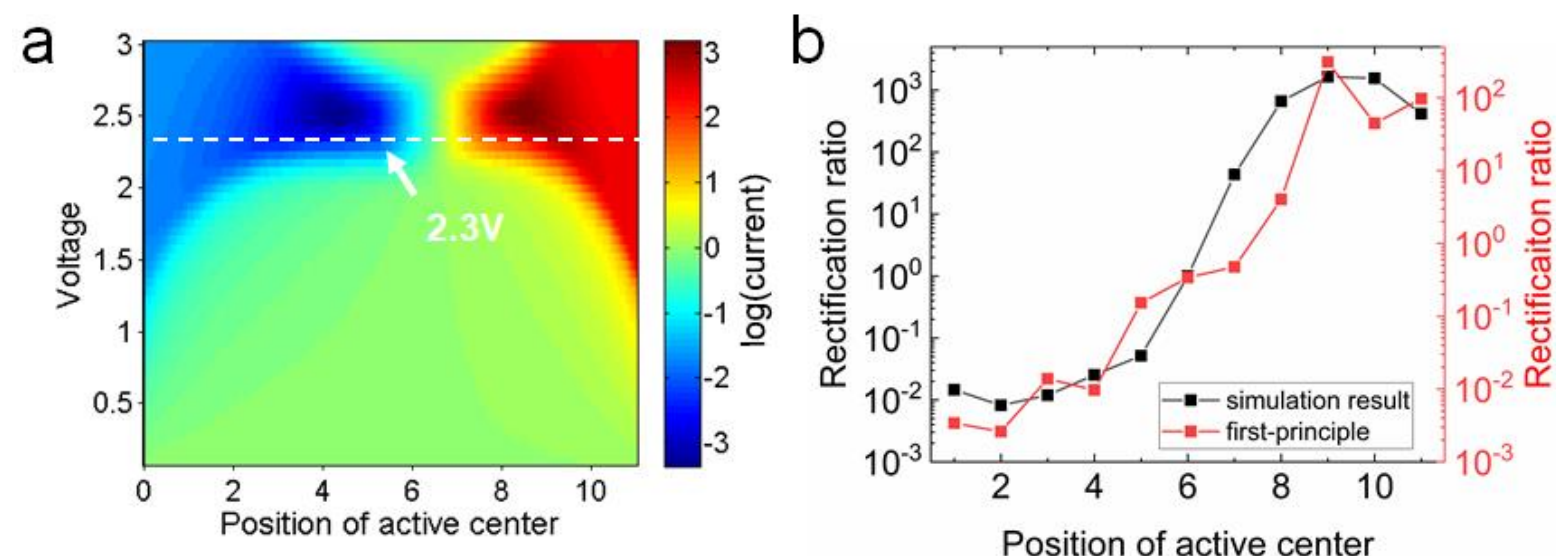

Figure S8 the rectification as a function of position of (a) bipyridyl group at full bias range at log-scale, (b) the rectification ratio changed as a function of position of bipyridyl group at $2.3 \mathrm{~V}$ compared with the first-principles results ${ }^{4}$. Parameter setting: $\varepsilon=1.37 \mathrm{eV}$, the coupling constant of molecule-right electrode $C_{R}=0.25 \mathrm{eV}$ and molecule-left electrode $C_{L}=0.05 \mathrm{eV}$. The X axis represents the number of carbon atoms at the left of group.

In this part, we simulated the work for calculating the rectification ratio of bipyridyl group at different position by using a first-principles method ${ }^{4}$. As shown in Figure S10, our results show good consistency with the first-principles results. The reasons for the parameters setting are as follows: $C_{R}$ roughly set the value that is less than $C_{B o t t o m}$ of ferrocene; $C_{L}$ that represent the coupling strength of bipyridyl group contacting Ag electrode set the value that is larger than the coupling strength of conjugated group contacting EGaIn electrode ${ }^{5}$.
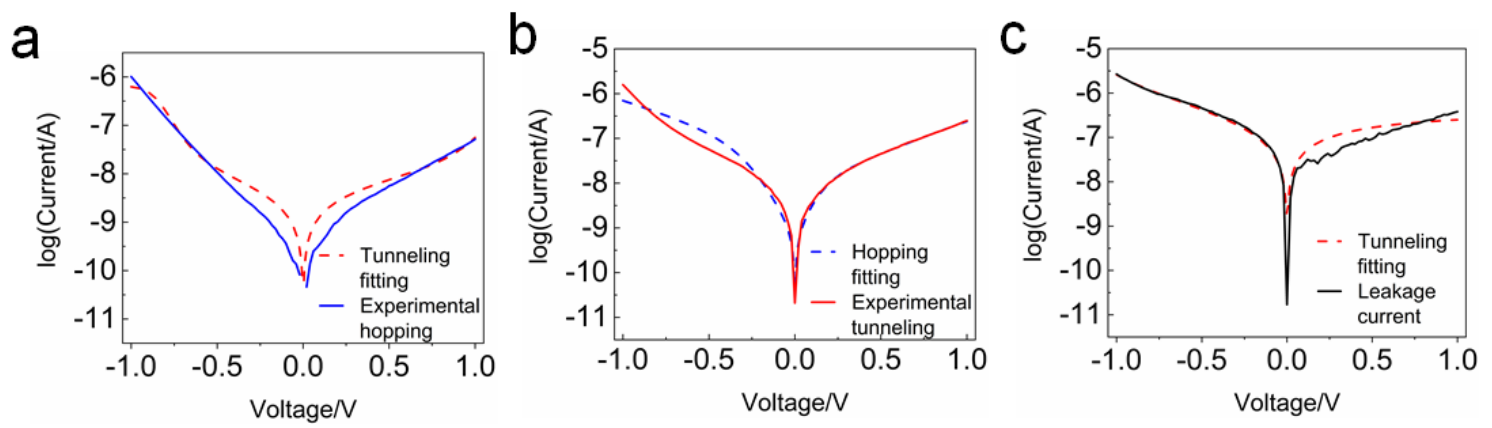

Figure. S9. (a) Tunneling fitting for region III (hopping transport), (b) hopping fitting for region II (tunneling transport), (c)Tunneling fitting for leakage current. (data extract from ref 9 in the main text) 
Table S1. Parameters extract from fitting results. The coupling strength is the total coupling strength.

\begin{tabular}{|c|c|c|c|c|c|}
\hline Molecule & $\begin{array}{c}\text { Coupling } \\
\text { strength }(e V)\end{array}$ & $\begin{array}{l}\text { Coupling } \\
\text { strength } 1\end{array}$ & $\begin{array}{l}\text { Coupling } \\
\text { strength } 2\end{array}$ & $\begin{array}{c}\text { Energy } \\
\text { barrier }(\mathrm{eV})^{*}\end{array}$ & $\begin{array}{c}\text { Voltage } \\
\text { division factor } \\
\left(\alpha_{L}\right) \\
\end{array}$ \\
\hline $\mathrm{SFcC}_{13}$ & 0.2714 & 0.0117 & 0.2597 & 0.3542 & 0.4731 \\
\hline $\mathrm{SC}_{1} \mathrm{FcC}_{12}$ & 0.0602 & 0.0547 & 0.0055 & 0.4672 & 0.4873 \\
\hline $\mathrm{SC}_{2} \mathrm{FcC}_{11}$ & 0.0773 & $\begin{array}{r}6.2910 \\
\times 10^{-4}\end{array}$ & 0.0766 & 0.4753 & 0.4448 \\
\hline $\mathrm{SC}_{3} \mathrm{FcC}_{10}$ & 0.0636 & 0.0632 & $\begin{array}{r}4.0048 \\
\times 10^{-4} \\
\end{array}$ & 0.5905 & 0.3235 \\
\hline $\mathrm{SC}_{4} \mathrm{FcC}_{9}$ & 0.0777 & 0.0771 & $\begin{array}{r}5.7545 \\
\times 10^{-4}\end{array}$ & 0.4772 & 0.4478 \\
\hline $\mathrm{SC}_{5} \mathrm{FcC}_{8}$ & 0.08664 & 0.08661 & $\begin{array}{r}3.0547 \\
\times 10^{-4}\end{array}$ & 0.472 & 0.4773 \\
\hline $\mathrm{SC}_{6} \mathrm{FcC}_{7}$ & 0.0685 & $\begin{array}{r}2.3457 \\
\times 10^{-4} \\
\end{array}$ & 0.0683 & 0.4819 & 0.4797 \\
\hline $\mathrm{SC}_{7} \mathrm{FcC}_{6}$ & 0.053 & $\begin{array}{r}4.7473 \\
\times 10^{-4}\end{array}$ & 0.0526 & 0.5014 & 0.5464 \\
\hline $\mathrm{SC}_{8} \mathrm{FcC}_{5}$ & 0.0535 & $\begin{array}{r}4.9710 \\
\times 10^{-4} \\
\end{array}$ & 0.0530 & 0.4928 & 0.5381 \\
\hline $\mathrm{SC}_{9} \mathrm{FcC}_{4}$ & 0.0508 & $\begin{array}{r}3.6596 \\
\times 10^{-4} \\
\end{array}$ & 0.0504 & 0.4558 & 0.5182 \\
\hline $\mathrm{SC}_{10} \mathrm{FcC}_{3}$ & 0.0471 & $\begin{array}{r}3.7479 \\
\times 10^{-4}\end{array}$ & 0.0467 & 0.5236 & 0.5805 \\
\hline $\mathrm{SC}_{11} \mathrm{FeC}_{2}$ & 0.0211 & $\begin{array}{r}1.9467 \\
\times 10^{-4} \\
\end{array}$ & 0.0209 & 0.5052 & 0.5901 \\
\hline $\mathrm{SC}_{12} \mathrm{FcC}_{1}$ & 0.0184 & $\begin{array}{r}3.8581 \\
\times 10^{-4}\end{array}$ & 0.0810 & 0.523 & 0.5941 \\
\hline $\mathrm{SC}_{13} \mathrm{Fc}$ & 0.0713 & 0.0705 & $\begin{array}{r}8.4845 \\
\times 10^{-5}\end{array}$ & 0.5743 & 0.7118 \\
\hline
\end{tabular}

* The energy barriers are of negative values in the model 
Table S2 Parameter setting for the reproduce result in the text

\begin{tabular}{|c|c|c|}
\hline Parameters & Figure 9 & Figure 10 \\
\hline Energy barrier $\Delta \varepsilon(\mathrm{eV})^{*}$ & 0.6 & 0.75 \\
\hline $\begin{array}{c}\text { Coupling strength } \\
C_{\text {bottom }}(\mathrm{eV})\end{array}$ & 0.35 & 0.35 \\
\hline $\begin{array}{c}\text { Coupling strength } \\
C_{\text {top }}(\mathrm{eV})\end{array}$ & 0.05 & 0.05 \\
\hline $\begin{array}{c}\text { Reorganization energy } \\
\lambda(\mathrm{eV})\end{array}$ & -- & 0.5 \\
\hline voltage division factor $\alpha$ & -- & $12 / 12^{\#}$ \\
\hline
\end{tabular}

* The energy barriers are of negative values in the model

\# 12/12 means that full bias localized in the molecule, while ignore the interface effect.

Table. S3. Parameters extract from tunneling fitting results

\begin{tabular}{|c|c|c|c|c|}
\hline Tunneling fitting & $\begin{array}{c}\text { Coupling } \\
\text { strength(eV) 1 }\end{array}$ & $\begin{array}{c}\text { Coupling } \\
\text { strength(eV) } 2\end{array}$ & $\begin{array}{c}\text { Energy } \\
\text { barrier(eV) }\end{array}$ & $\begin{array}{c}\text { Voltage division } \\
\text { factor }\end{array}$ \\
\hline Region II & $1.0882 \times 10^{-5}$ & 0.0626 & $0.5508^{*}$ & 0.5578 \\
\hline
\end{tabular}

Table. S4. Parameters extract from hopping fitting results

\begin{tabular}{|c|c|c|c|c|c|}
\hline $\begin{array}{c}\text { Hopping } \\
\text { fitting }\end{array}$ & Rate 1( $\left.\mathrm{s}^{-1}\right)$ & Rate $2\left(\mathrm{~s}^{-1}\right)$ & $\begin{array}{c}\text { Energy } \\
\text { barrier(eV) }\end{array}$ & $\begin{array}{c}\text { Reorganization } \\
\text { energy(eV) }\end{array}$ & $\begin{array}{c}\text { Voltage } \\
\text { division } \\
\text { factor }\end{array}$ \\
\hline Region III & $\begin{array}{l}5.8144 \\
\times 10^{10}\end{array}$ & $\begin{array}{c}3.2009 \\
\times 10^{12}\end{array}$ & $0.1231^{*}$ & 0.9665 & 0.2420 \\
\hline
\end{tabular}

* The energy barriers are of negative values in the model 


\section{References}

1. Nitzan, A.; Galperin, M.; Ingold, G. L.; Grabert, H., On the electrostatic potential profile in biased molecular wires. J. Chem. Phys. 2002, 117 (23), 10837-10841.

2. Mujica, V.; Roitberg, A. E.; Ratner, M., Molecular wire conductance: Electrostatic potential spatial profile. The Journal of Chemical Physics 2000, 112 (15), 6834-6839.

3. Yuan, L.; Nerngchamnong, N.; Cao, L.; Hamoudi, H.; del Barco, E.; Roemer, M.; Sriramula, R. K.; Thompson, D.; Nijhuis, C. A., Controlling the direction of rectification in a molecular diode. Nat Commun 2015, 6,6324 .

4. Zhang, G.-P.; Wang, S.; Wei, M.-Z.; Hu, G.-C.; Wang, C.-K., Tuning the Direction of Rectification by Adjusting the Location of the Bipyridyl Group in Alkanethiolate Molecular Diodes. The Journal of Physical Chemistry C 2017, 121 (14), 7643-7648.

5. Cho, S. J.; Kong, G. D.; Park, S.; Park, J.; Byeon, S. E.; Kim, T.; Yoon, H. J., Molecularly Controlled Stark Effect Induces Significant Rectification in Polycyclic-Aromatic-Hydrocarbon-Terminated n-Alkanethiolates. Nano Lett. 2019, 19 (1), 545-553.

6. Valianti, S.; Cuevas, J. C.; Skourtis, S. S., Charge-Transport Mechanisms in Azurin-Based Monolayer Junctions. J. Phys. Chem. C 2019, 123 (10), 5907-5922.

7. Kastlunger, G.; Stadler, R., Density functional theory based direct comparison of coherent tunneling and electron hopping in redox-active single-molecule junctions. Phys. Rev. B 2015, 91 (12), 125410.

8. Simmons, J. G., Generalized Formula for the Electric Tunnel Effect between Similar Electrodes Separated by a Thin Insulating Film. J. Appl. Phys. 1963, 34 (6), 1793-1803.

9. Migliore, A.; Nitzan, A., Irreversibility and hysteresis in redox molecular conduction junctions. J. Am. Chem. Soc. 2013, 135 (25), 9420-32.

10. Arielly, R.; Vadai, M.; Kardash, D.; Noy, G.; Selzer, Y., Real-Time Detection of Redox Events in Molecular Junctions. J. Am. Chem. Soc. 2014, 136 (6), 2674-2680.

11. Chidsey, C. E. D., Free Energy and Temperature Dependence of Electron Transfer at the Metal-Electrolyte Interface. Science 1991, 251, 919-922.

12. Weiss, E. A.; Chiechi, R. C.; Kaufman, G. K.; Kriebel, J. K.; Li, Z. F.; Duati, M.; Rampi, M. A.; Whitesides, G. M., Influence of defects on the electrical characteristics of mercury-drop junctions: Self-assembled monolayers of n-alkanethiolates on rough and smooth silver. J. Am. Chem. Soc. 2007, 129 (14), 4336-4349.

13. Thuo, M. M.; Reus, W. F.; Nijhuis, C. A.; Barber, J. R.; Kim, C.; Schulz, M. D.; Whitesides, G. M., Oddeven effects in charge transport across self-assembled monolayers. J. Am. Chem. Soc. 2011, 133 (9), 2962-75.

14. Garrigues, A. R.; Yuan, L.; Wang, L.; Mucciolo, E. R.; Thompon, D.; Del Barco, E.; Nijhuis, C. A., A SingleLevel Tunnel Model to Account for Electrical Transport through Single Molecule- and Self-Assembled Monolayer-based Junctions. Sci. Rep 2016, 6, 26517. 